\title{
Faculty Perspectives on Factors Promoting Effective RN to BSN Completion Programs
}

\author{
Renee Hoeksel ${ }^{1, *}$, Suzanne Sikma ${ }^{2}$, Mary Baroni \\ ${ }^{1}$ College of Nursing, Washington State University, Vancouver, USA \\ ${ }^{2}$ Retired from School of Nursing \& Health Studies, University of Washington, Bothell, USA
}

Email address:

rhoeksel@wsu.edu (R. Hoeksel)

${ }^{*}$ Corresponding author

To cite this article:

Renee Hoeksel, Suzanne Sikma, Mary Baroni. Faculty Perspectives on Factors Promoting Effective RN to BSN Completion Programs. Education Journal. Vol. 9, No. 6, 2020, pp. 195-202. doi: 10.11648/j.edu.20200906.16

Received: December 8, 2020; Accepted: December 16, 2020; Published: December 31, 2020

\begin{abstract}
The need for a more highly educated nursing workforce has been well established. The need for BSN-prepared nurses continues to escalate and more registered nurse to bachelor of science in nursing (RN to BSN) programs are approved in Washington State every year. RN to BSN completion programs provide an efficient bridge for diploma and associate degree (ADN) nurses to progress academically and advance their careers. This multi-method, descriptive study was designed to identify common elements and promising practices for curricular and program design across seven of the nine RN to BSN programs in the state of Washington. Program directors compiled institutional data and a confidential online survey was sent to faculty who were teaching in each program. The University of Washington School of Social Work Survey Research Division (SRD) was contracted to administer the online surveys. SPSS was utilized for quantitative data analysis, while the investigative team used standard content analysis techniques for the qualitative items. Sixty-two of the 82 faculty surveys were returned (75.6\%) and all seven programs provided extensive institutional data. This report explains mainly the faculty responses, while noting areas for immediate improvement including the statewide failure to gather important student demographic data like race and ethnicity. Given the wide diversity of this student population, and the profession's drive to diversify the workforce, failure to carefully monitor these data needs action. Characteristics of the wide range in student readiness for BSN-level coursework and rigors of work/life balance, along with the dynamic nature of RN to BSN education, were consistently brought forward by faculty, independent of years of teaching experience.
\end{abstract}

Keywords: Academic Progression, RN to BSN Completion, Nursing Faculty

\section{Introduction}

In response to the 2011 Institute of Medicine [1] Future of Nursing Report recommendations, as well as healthcare employer demands for a more highly educated nursing workforce, the number of $\mathrm{RN}$ to $\mathrm{BSN}$ education programs has grown to 777 , with more than 600 offered at least partially online. In addition to the growth in number of programs, there is a 15-year history of increases in RN to BSN graduations [2]. A current projection model [3] requires continued growth in the number of RN to BSN graduates in order to reach the goal of $80 \%$ of registered nurses (RNs) with baccalaureate degrees or higher by 2025 [4].

In the last 15 years, the literature reflects a body of evidence suggesting a positive relationship between baccalaureate or higher education of nursing staff and better outcomes for patients [5-9]. Economic analyses [10, 11] suggest a positive relationship between the education level of nursing staff and organizational outcomes [12].

$\mathrm{RN}$ to BSN completion programs provide an efficient bridge for diploma and associate degree (ADN) nurses to progress academically and advance their careers [13, 14]. These programs build on pre-licensure preparation providing coursework designed to: 1) enhance professional development; 2) prepare for a broader scope of practice; and, 3) provide a better understanding of the cultural, political, economic, and social issues that affect patients and influence care delivery [2]. Despite the commonalities in this description, $\mathrm{RN}$ to $\mathrm{BSN}$ program length varies depending on university requirements, 
program configuration and students' previous academic achievement. Program structures differ, creating varying demands on faculty. Some faculty may be simultaneously teaching both pre-licensure and RN to BSN students at the same school, or may have heterogeneous classes with mixtures of both types of students, while others teach classes exclusively composed of registered nurse students. Many programs have entered into innovative partnerships with hospitals and/or community colleges to increase off-site access to RN to BSN education. This may pose unique faculty challenges and opportunities. Individual schools more commonly offer both pre-licensure and RN to BSN programs, while some may concentrate exclusively on RN to BSN education. Because online or blended approaches seem to be popular, faculty face the challenge of effectively using a variety of distance learning approaches and educational technologies to reach students in disparate geographic sites while others may be literally "going the extra miles" to provide face-to-face options at off-site locations. In the face of increasing demand, however, there is little evidence available describing distinctive characteristics of RN to BSN students warranting special teaching strategies, such as online/blended learning approaches, or how RN to BSN faculty are prepared and supported in using these modalities. Further, there is a paucity of evidence regarding program configurations that promote quality in RN to BSN education, seamless academic progression, minimize faculty challenges, and address ongoing faculty development needs. The current study was designed as part of the Washington State Academic Progression in Nursing grant in order to provide more insight into these gaps [15].

Washington State provided a fertile context for this study. Increasing access to quality RN to BSN education has been a priority in the state for over a decade, as highlighted in the Master Plan for Nursing Education in Washington State [16]. The state offers RN to BSN programs in a variety of settings: 1) long-established university-based programs within schools/colleges of nursing; 2) universities without pre-licensure nursing programs; and, 3) Washington was a pioneer in offering the RN to BSN degree in a community college setting [17]. In addition, online learning technologies are used to varying extents across all these settings.

Washington State is unique in its statewide efforts, not only including the diversity of venues in which $\mathrm{RN}$ to BSN education is provided, but also in support for expansion of regulatory oversight of post-licensure nursing education programs to assure geographical access, enrollment capacity, and quality pedagogy for RN to BSN education [18]. While the majority of state boards of nursing review and approve pre-licensure RN programs, the Washington State board of nursing titled the Nursing Care Quality Assurance Commission (NCQAC) extended its oversite in 2013 to review all post-licensure programs, including approval for practice experiences for out-of-state nursing education programs wishing to enroll Washington State nurses [18]. NCQAC reviews and authorizes all RN to BSN programs operating in the state, and collects annual data about registration and graduations. Annual graduations from RN to BSN programs increased by $310 \%$ from 2006-2016, and enrollments have more than quadrupled in the same time period. In academic year 2016-2017, enrollments and graduations continued to increase, with 2,582 students enrolled and 1,319 graduates from RN to BSN programs in the state [19].

\section{Methods}

\subsection{Design}

This multi-method, descriptive study was designed to identify common elements and promising practices for curricular and program design across $\mathrm{RN}$ to $\mathrm{BSN}$ programs in the state of Washington. Seeking to uncover the factors that promote quality and advance the Washington RN workforce towards the IOM goal to increase the portion nurses with baccalaureate degrees to $80 \%$ by 2020 , the study had the following specific aims:

Describe characteristics of the RN to BSN student population that have implications for program design and assurance of quality pedagogy.

Describe perceptions of faculty roles and the challenges and benefits of teaching the student population in RN to BSN programs.

Describe strategies for optimal preparation, orientation and ongoing professional development of RN to BSN faculty.

Describe successful pedagogical approaches \& technology use for facilitating learning in the RN to BSN student population.

\subsubsection{Sample and Setting}

At the time of study initiation, there were nine NCQAC-approved RN to BSN programs in Washington State. The Dean or Director (hereafter titled Director) of each program was sent an informational email inviting study participation. Following consultation with their faculty, seven of the nine in-state programs agreed to participate. All participants were teaching $\mathrm{RN}$ to BSN courses and/or directing $\mathrm{RN}$ to BSN programs and sampling was done by online surveys. The seven participating schools reflected the variations in institutional structures in Washington State including three public universities, two private universities, and two community colleges, with cohort options in 16 different locations in the state. In addition to the seven home campuses for each school, options for taking courses were available at four hospitals, two community colleges hosting space for two different university-based programs, and three free-standing outreach sites not specifically associated with a community college or hospital.

\subsubsection{Instruments and Procedures}

The University of Washington School of Social Work Survey Research Division (SRD) was contracted to administer the online surveys. The SRD staff provided final online formatting of the surveys; managed the distribution, the reminders and data management for both surveys; prepared 
the datasets for the researchers; and administered the incentive gift card distribution to the faculty survey participants.

The project phase reported here was a confidential online survey of faculty teaching in the seven participating $R N$ to BSN programs. Directors provided a roster of faculty names and email addresses to the SRD for survey distribution. The survey link was distributed via email by the SRD to faculty members teaching at least part-time in one of the seven participating $\mathrm{RN}$ to $\mathrm{BSN}$ programs $(\mathrm{n}=82)$. This survey link was active for eight weeks with reminders sent at weeks one, three, four, six, and eight to potential participants that had not yet responded. Upon survey completion, the SRD mailed the respondent a $\$ 50$ faculty incentive gift card. Survey variables of interest included faculty perspective on their role in $\mathrm{RN}$ to BSN education and what professional development support is necessary to enhance faculty capacity in working with this non-traditional student population. Table 1 summarizes the variables of interest in the Faculty Survey and questions used to measure each variable.

Table 1. Faculty Survey Variables and Measures.

\begin{tabular}{|c|c|}
\hline Faculty Survey Variables & Measures \\
\hline \multirow{5}{*}{ Characteristics of Faculty Respondents } & Q6 Description of faculty appointment \\
\hline & Q11 Venues in which you have taught RNB \\
\hline & Q12 Responsibilities of current position \\
\hline & Q13 Research/scholarship expectations \\
\hline & Q14 Past education related to teaching \& learning \\
\hline $\begin{array}{l}\text { Perceptions of Characteristics of } R N \text { to } B S N \\
\text { Student Population }\end{array}$ & Q27 Describe the distinctive characteristics of the RNB student population you teach \\
\hline \multirow{3}{*}{ Perceptions of the Faculty Role } & Q17 Significant challenges of RNB faculty role? \\
\hline & Q18 Positive aspects of RNB faculty role? \\
\hline & Q19 What aspects of your RNB program enhance your capacity to meet student needs? \\
\hline \multirow{4}{*}{ Faculty Preparation \& Development } & Q21 Self-assessment of skill in instructional technologies \\
\hline & Q22 Rate adequacy of orientation to instructional technologies \\
\hline & Q23 Support for instructional technologies \\
\hline & Q28 What knowledge, skills and attitudes are necessary in successfully working with RNB students? \\
\hline
\end{tabular}

\subsection{Protection of Human Subjects}

Study procedures were reviewed and approved by the human subject review entities at the investigators' respective institutions. The link for each online survey began with an informational statement noting that participation was voluntary and could be discontinued at any time. The completion of the online survey indicated the participant fully volunteered and was accepted in lieu of a written consent.

The SRD prepared the confidential online survey data files. Because the investigators were faculty members in participating programs, specific names of online faculty survey participants remained confidential only to the SRD. Faculty demographic data were reported in aggregate only, and were not linked with individual responses. Only the SRD had access to confidential information regarding faculty respondent names and addresses. Having this information allowed for targeted email reminders to non-respondents, and distribution of gift cards upon survey completion.

\subsection{Data Analysis}

The SRD compiled the data collected from the surveys and provided it to the investigators in SPSS Statistics 23(IBM, 2016) format. Quantitative items on the survey instruments were summarized with descriptive statistics using the SPSS Statistics 23 program (IBM, 2016). Qualitative items on the survey instruments were responses to open-ended questions and directly downloaded as verbatim transcripts. The analytic team, composed of three investigators, analyzed these transcripts using conventional qualitative content analysis procedures [20] supplementing the deductive approach with inductive coding of additional ideas that appeared in the data [21]. NVivo Pro 11 was the program used for qualitative analysis (QSR International, 2016).

\section{Results}

Seven RN to BSN programs and their faculty, representing $78 \%$ of the in-state approved programs, participated in the surveys. An online faculty survey link and reminders were sent via email to 82 faculty members, and 62 online faculty surveys were completed (75.6\% response rate).

A notable segment (38\%) had less than five years in their current faculty role, and $25 \%$ of the respondents had less than five years teaching nurses. Mid-career faculty (5-14 years of experience) represented the largest segment of the respondents, with $43 \%$ having this range of experience in their current faculty position, and $48 \%$ within this range of experience teaching nurses. Late career faculty $(15-20+$ years of experience) comprised $20 \%$ of the sample with this length of experience in their current position.

Table 2 reflects further demographics of the faculty survey respondents. 
Table 2. Faculty Demographics.

\begin{tabular}{|c|c|c|c|}
\hline & Full-Time Faculty $(n=37)$ & Part-Time Faculty $(\mathrm{N}=38)$ & Total $(\mathrm{N}=75)$ \\
\hline Mean Age (Range) & 56.5 years $(33-78)$ & 54.6 years $(35-76)$ & \\
\hline \multicolumn{4}{|l|}{ Age Distribution } \\
\hline $30-39$ years & $5.4 \%(2)$ & $15.7 \%(5)$ & $10.2 \%(7)$ \\
\hline $40-49$ years & $18.9 \%(7)$ & $18.8 \%(6)$ & $18.8 \%(13)$ \\
\hline $50-59$ years & $27.0 \%(10)$ & $21.8 \%(7)$ & $24.6 \%(17)$ \\
\hline$>60$ years & $48.7 \%(18)$ & $43.8 \%(14)$ & $46.4 \%(32)$ \\
\hline \multicolumn{4}{|l|}{ Gender } \\
\hline Female & $91.9 \%(34)$ & $89.5 \%(34)$ & $90.7 \%(68)$ \\
\hline Male & $8.1 \%(3)$ & $10.5 \%(4)$ & $9.3 \%(7)$ \\
\hline \multicolumn{4}{|l|}{ Tenure vs Non-Tenure Track } \\
\hline Non-Tenure Track & $21.6 \%(8)$ & $94.7 \%(36)$ & $58.7 \%$ (44) NTT Total \\
\hline Tenure Track & $27.0 \%(10)$ & & $41.3 \%$ (31) TT Total \\
\hline Tenured & $51.4 \%(19)$ & $5.3 \%(2)$ & \\
\hline Salaries & FT Faculty Annual Salaries & Part-Time Monthly Salaries & \\
\hline Mean (Range) & $\$ 81,806(\$ 57,005-\$ 173,064)$ & $\$ 5,673(\$ 600-\$ 9,608)$ & \\
\hline Without Outlier & $\$ 79,271(\$ 57,005-124,884)$ & & \\
\hline \multicolumn{4}{|l|}{ Teaching Responsibilities } \\
\hline RN-to-BSN Courses & $100.0 \%(34)$ & $100.0 \%(33)$ & \\
\hline Pre-Licensure RN & $64.7 \%(22)$ & $60.6 \%(20)$ & \\
\hline Non-Nursing & $29.4 \%(10)$ & $48.5 \%(16)$ & \\
\hline \multirow{2}{*}{ Master's Level Doctoral Level } & $17.7 \%(6)$ & $48.5 \%(16)$ & \\
\hline & $29.4 \%(10)$ & ---- & \\
\hline
\end{tabular}

Characteristics of the RN to BSN student population do have implications for program design and assurance of quality pedagogy. Descriptive characteristics of the student population were compiled from data provided on the institutional survey, as well as qualitative comments from the participating faculty. Unfortunately, in the institutional survey, there were significant missing data on student demographics including: 1) matriculation of new $\mathrm{RN}$ vs experienced $\mathrm{RN}$ students; 2) first generation college students; non-native English-speaking students; 3) gender identity; and, 4) military veteran status. The requested student demographic variables were inconsistently gathered across institutions by different entities utilizing different data systems within the institutions. This sometimes made it difficult for leaders in the nursing program to obtain and/or extract the requested student information. However, despite the limitations of the institutional quantitative data, faculty comments provided considerable insight into the growing diversity of RN to BSN students.

Qualitative analysis of faculty survey responses reflected four themes. The first is the wide demographic diversity of RN to BSN students. Responses described the diversity in race, ethnicity, culture, age, gender identity and sexuality among the students. Descriptors included phrases such as "diverse in age, ethnicity and gender," "some second/third career students," "many English-language learners," "many immigrants," and, "high proportion of first-generation college students."

A second theme describing the $\mathrm{RN}$ to $\mathrm{BSN}$ student population is that they have a wide range of readiness for upper division academic skills (reading, writing, language, technology). Faculty comments supporting this theme included the following statements: 1) "diverse in ADN program's preparation of them for $\mathrm{RN}$ to BSN completion program"; 2) "It is a big step up for students who have never attended a university before."; 3) "Students seem to focus on tasks more than critical thinking... have little time to think reflectively...usually not interested in any extra learning opportunities...want to go through the program as fast as possible with as little hassle as possible."; 4) "Many students have poor writing skills. That said...they are very eager to learn and want to do well...Most are driven, hardworking."; and, 5) "Students are open to learning new material, aware of the positive effects of program on themselves and are engaged with course material. They are also reluctant to go above and beyond set expectations, complain often if things are not clear or they feel they are too difficult, and are unlikely to communicate with the professor except to ask about scoring of a particular assignment."

A third theme describing the students is that they have a wide range of professional experiences and expertise from novice to expert. A comment supporting this theme is:

"Previously, students were mostly practicing RNs who were motivated by self-growth and...career changes requiring a different degree, students who were mostly mature in their expectations, had experiences to share, and moved through the courses at the advised pace. In the past 3-5 years, there has been an increase in new ADN grads whose place of work or condition of hire is to get a BSN. They are mostly younger, enjoy technology and can use new platforms more easily, learn 'differently' due to their past history with tech tools since their toddler years, have high and sometimes unrealistic expectations of themselves. They seem to want their education "quick, down and dirty."

The fourth theme reflects the significant work-life demands on this population of students. Faculty comments include: 1) "Because of their life demands, they are on campus only one day per week for classes," 2) "Students are managing an incredible work-school-life balance...working very hard to maintain either their established work schedule or their new 
role as a graduate nurse. All have some experience needing to prioritize life-events into the context of their education. All require extensive support and mentorship that goes beyond that of traditional baccalaureate students."; and, 3) "The complexity of their lives is overwhelming... and they need strong guidance in learning how to determine priorities that may not always lead to receiving a 4.0 GPA, but still acquiring the knowledge for advancing their professional practice."

Faculty survey findings reflect self-rated competence and faculty perceptions of the knowledge, skills and attitudes (KSA) necessary to be an effective $\mathrm{RN}$ to $\mathrm{BSN}$ program faculty. Over one-third (36.1\%) of the faculty rated themselves as novice teachers, which is the exact same percentage who rated themselves as competent. Faculty also self-rated their competence in using Instructional Technologies. The majority $(63.5 \%)$ of faculty rated their competency in using learning management systems such as Blackboard or Canvas as proficient or expert. However, no other self-ratings of proficient/expert competence in using instructional technologies were above $33 \%$ (see Table 3 ).

Table 3. Faculty Self-rated Competencies.

\begin{tabular}{ll}
\hline Item & Results \\
\hline Level of Teaching Competence & \\
None/Novice & $36.1 \%$ \\
Competent & $36.1 \%$ \\
Proficient & $26.2 \%$ \\
Expert & $1.6 \%$ \\
Total & $100 \%$ of respondents \\
Competence with Instructional & $\%$ of respondents saying YES \\
Technologies & $61.3 \%$ \\
Video/digital story telling software & $61.0 \%$ \\
Lecture capture & $60.7 \%$ \\
Brick\& mortar simulation labs & $54.7 \%$ \\
Mobile learning technologies & $50.0 \%$ \\
Lecture or quiz testing software & $46.1 \%$ \\
Social networking as learning tools & $44.2 \%$ \\
Collaborative online file sharing & $43.6 \%$ \\
Webinar/web-conferencing software & $43.1 \%$ \\
E-portfolio software & $39.5 \%$ \\
\hline Learning analytics &
\end{tabular}

The faculty survey responses also included a description of teaching competencies necessary in RN to BSN education. Qualitative analysis of these responses reflects the KSA faculty deem important. These KSA include: 1) valuing engagement with students; 2) having pedagogical range and flexibility; 3) promoting diversity and inclusion; 4) facilitating application of knowledge to practice; 5) applying adult learning principles and problem-based learning; 6) using e-learning; and, 7) maintaining standards and rigor across all these approaches.

Faculty survey findings included perceptions of strategies for optimal preparation, orientation and ongoing professional development. Helpful role preparation and continuing faculty development were two categories identified. The first category included strategies for role preparation and continuing faculty development across the continuum of experience. Both novice and experienced faculty members identified the same two strategies as the most helpful: 1) mentorship, collaboration \& consultation from experienced faculty members; and, 2) support (release time, travel and conference expenses/fees) to participate in faculty development activities (courses, workshops, conferences, etc.) that help expand pedagogical expertise in both breadth \& depth.

The second category of support for faculty development addressed program structural factors that enhance faculty capacity. These included: pro-active student advising; academic support services (reading/writing, quantitative, library/information literacy); both availability for students and for collaboration with faculty in courses; availability of faculty peers and mentors;

Information technology support and a learning management system to facilitate online learning; clinical placement support; reasonable class size and workload (balance of teaching-research-service); autonomy/academic freedom; program leadership; strong community partners and alumni; commitment to accessibility \& student-centeredness; and, a well-designed curriculum.

Faculty respondents preferred to teach these students by hybrid course delivery $(51.6 \%)$, followed by face to face $(40.6 \%)$ and totally online $(7.9 \%)$. Successful pedagogical approaches and technology used to facilitate learning in the $\mathrm{RN}$ to BSN student population were explored in-depth. These approaches (with illustrative direct quotes/examples from faculty respondents) revealed:

Active and student-led learning activities: "In leadership \& policy course, they identify an issue, develop a policy brief, and then pursue an advocacy project. Throughout, they receive extensive feedback on their public speaking skills and their ability to communicate the message of their work to an audience they wish to influence. The culmination of the project is a demonstration of their speaking skill in providing a persuasive 5-7 minute talk."

Integration of content learning and academic/professional skill development: "Academic support service staff help us plan assignments (for writing and information literacy skill development) and provide support to students on and off campus."

Providing space for choice in learning activities: "I provide a variety of reading and video options related to the learning outcomes and let the students choose what interests them. For the final project, to assess meeting learning outcomes, there are choices of topic and format as well. This supports the adult learner with individual learning goals and needs and supports multiple ways of knowing and learning."

Making connections and applications for practice: "I spend part of first 2 weeks really making the connection between what we are going to be learning in this class and why it is relevant to nursing practice."

Use of carefully structured and managed diverse, small groups: "I like small group work and finding ways to help students apply theory to practice in ways that are meaningful to them. I set expectations which align with course objectives and materials. Groups have class time to work on their project and a Canvas page for posting their material (online). This culminates in some really innovative presentations and an 
annotated bibliography. This assignment lets them grapple with objectives and materials while also engaging their real-life experiences and their creativity."

Scaffolding of learning: "Scaffold small writing assignments/exercises to culminate in a large final written paper assignment."

Use of a variety of media and learning technology: "Use a variety of film, media, Tegrity lectures, [and] online discussion forums. This use of technology supports the concept of the "flipped" classroom which frees class time to focus on concepts the students need assistance with as well as application of these concepts."

Reflective learning activities: "Students are expected to do weekly reading engagement logs where they interact personally with the reading assignments (not just summarizing the material) and this becomes a basis for both classroom discussion and personal engagement on certain issues and questions."

Community-based learning activities: "CBL is a powerful learning tool. In a global women's health course, students worked with pre-selected community partners...to complete a project relative to a women's health issue... (with a product) reflecting on how the project impacted their understanding of the course information and objectives." "Even with their busy schedules and life demands, the students indicated in their course evaluations that the service-learning project should remain, and that it did enhance their motivation and engagement as well as overall learning."

Use of ungraded assignments: "I do not grade each assignment. I require (an assignment) be revised until it meets the objectives. The students have required assignments to earn a certain grade and optional assignments to earn a higher grade. This works well as students who are being asked to think and write in new ways are not concerned about getting an ' $\mathrm{F}$ ' and instead focus on new learning. The learning becomes the goal rather than the grade."

\section{Discussion and Application}

The study findings provide valuable insight into the factors that promote effective $\mathrm{RN}$ to BSN completion programs. Options in Washington state for registered nurses to return for their BSN degree continue to increase. In September 2019 there were 16 approved in-state and 20 approved out of state programs [22].

These $\mathrm{RN}$ to $\mathrm{BSN}$ programs are showing significant increases in total enrollments and graduations, as well as low attrition rates and capacity for further growth. This growth represents both a challenge and an opportunity for nurse educators as they strive to mitigate and overcome the many barriers that RNs may encounter in trying to obtain their BSN [23-25].

The national trends showing the aging faculty workforce were reflected in our findings with $47 \%$ of full-time and $41 \%$ of part-time faculty being over 60 years of age [25]. Given anecdotal reports that RN to BSN students tend to be more diverse, non-traditional students, the lack of consistent tracking of demographic data by multiple schools, and thus statewide was concerning and should be addressed.

All participating programs were using hybrid venues for their RN to BSN programs, while faculty self-rated competence in using instructional technologies suggests the likely need for further faculty development. With many RN to BSN educational programs moving to hybrid or distance-learning models, the need to assure faculty competencies with new and emerging instructional technologies is imperative [26, 27]. Inconsistent practices in orientation and mentorship, as well as the faculty role common in the nursing education literature were frequently mentioned by our study respondents.

Rarely seen in the nursing literature is the notion of key practice elements, which present both rewards and challenges to nurse educators regardless of their years of experience [28, 29]. Creating meaningful learning experiences was frequently seen as both a reward/opportunity and a challenge, which is not surprising given the dynamic characteristics of the healthcare system and RN to BSN education. Level of student engagement and motivation was also seen by the majority of respondents as both an opportunity and a challenge, which confirms findings by other investigators [30].

\section{Application to Clinical Practice}

What constitutes quality "clinical" learning activities in RN to BSN programs also continues to be seen as an opportunity and a challenge. Anecdotally, faculty see requests from newly graduated nurses for more faculty-guided clinical hours, while experienced nurses want as few hours as possible [22]. In 2014, The Washington Nursing Commission (NCQAC) established that all RN to BSN programs must have a minimum of 100 practice hours in their curriculum, causing most programs to modify their courses to meet this requirement [31]. Some programs, especially those from out of state, may see this as a barrier to approval, yet others have embraced the regulation as a way to find innovative ways to guide students in BSN-level nursing practice.

Perfetto's synthesis of the literature regarding best practices for distance/online/hybrid RN to BSN program curriculums identified the importance of deliberate planning for programs and courses [32]. These findings outline the successful outcomes $(<1 \%-3 \%$ attrition) accomplished in the sample schools through faculty development, as well as deliberate, collaborative planning with academic and instructional staff support resources for online and hybrid courses [32]. They further reflect the utility of programs featuring cohort models with classes one day a week to promote development of a learning community. The findings and pedagogical approaches described in this study further elaborate and support Perfetto's observation that student engagement, application of learning to practice, carefully structured and managed group work, and community-based learning activities contribute to student retention and successful program completion [32].

Study limitations are those commonly associated with 
descriptive designs and convenience sampling. Although two $\mathrm{RN}$ to BSN programs declined to participate, the seven programs that did respond represented 16 different physical locations across Washington State. This enabled the researchers to capture diverse geographical settings including large urban, remote rural, and growing suburban locales.

Purposive convenience sampling brought further limitations, yet the excellent $(75.6 \%)$ return rate from (mostly full-time) faculty surveys gathered perspectives and evidence from targeted stakeholders immersed in RN to BSN education. Though employed at seven different schools of nursing, all informants were from one region of the Pacific Northwest. The survey questions were developed by the three investigators based upon their extensive experience in $\mathrm{RN}$ to BSN programs as both faculty and administration (combined $>75$ years), as well as a comprehensive review of the literature.

\section{Conclusion}

The current multi-method descriptive study identified common elements and promising practices for curricular and program design across $\mathrm{RN}$ to $\mathrm{BSN}$ programs in the state of Washington, where increasing access to quality RN to BSN education has been a top priority for the last decade. Characteristics of the wide diversity in student readiness for BSN-level coursework and rigors of work/life balance, along with the dynamic nature of $\mathrm{RN}$ to $\mathrm{BSN}$ education, were consistently brought forward by faculty, independent of years of teaching experience.

Best practices for teaching in $\mathrm{RN}$ to $\mathrm{BSN}$ programs include: 1) a deep understanding of the characteristics and context of students' lives; 2) developing the KSA important to provide rigorous and meaningful learning experiences; and, 3) utilizing a wide range of strategies to engage these students actively in the learning process. Programs need to invest in a commitment to faculty development and other program resources that enhance faculty capacity in their teaching role.

\section{Acknowledgements}

This study was funded by Grant \#71948 from the Robert Wood Johnson Foundation, Academic Progression in Nursing Program to the Washington Center for Nursing (WCN). The authors would also like to acknowledge Danielle Woodward and staff at the Survey Research Division of the Social Development Research Group at the University of Washington for their assistance with online survey instrument development and administration. Also, Kristi Cunnington MN, $\mathrm{RN}$ for assistance with data analysis; Sofia Aragon, WCN Executive Director and Olena Rypich, WCN Communications Director for their assistance with project facilitation and dissemination; and members of the Council of Nurse Educators in Washington State for their review and comments on preliminary findings.

\section{References}

[1] Institute of Medicine (2011). The Future of Nursing: Leading Change, Advancing Health. Washington, DC: The National Academies.

[2] AACN. Fact Sheet: Degree Completion Programs for Registered Nurses: $R N$ to Master's Degree and $R N$ to Baccalaureate Programs. Retrieved from https://www.aacnnursing.org/Portals/42/News/Factsheets/Degr ee-Completion-Factsheet.pdf. (2019).

[3] Spetz, J (2018). Projections of progress toward the $80 \%$ Bachelor of Science in Nursing recommendation and strategies to accelerate change. Nursing Outlook (66), 394-400.

[4] McEwen, M., Pullis, B., White MJ., and Krawtz, S. (2013). Eighty percent by 2020: The present and future of RN-to-BSN education. Journal of Nursing Education, 52(10), 549-557.

[5] Aiken, L.H., Clarke, S., Cheung, R., Sloane, D. and Silber, J. (2003) Educational levels of hospital nurses and surgical patient mortality. Journal of the American Medical Association, 290(12), 1617-1623.

[6] Aiken LH, Cimmiotti JP, Sloane DM, Smith HL, Flynn L, Neff DF. (2012) The effects of nurse staffing and nurse education on patient deaths in hospitals with different nurse work environments. Med Care 49(2): 1047-1053.

[7] Blegen, MA, Goode, CJ, Park, SH, Vaughn, T \& Spetz, J. (2013). Baccalaureate education in nursing and patient outcomes. Journal of Nursing Administration 43(2), 89-94.

[8] Friese, C. R, Lake, E.T., Aiken, L.H., Silber, J.H. \& Sochalski, J. (2008, August). Hospital nurse practice environments and outcomes for surgical oncology patients. Health Services Research, 43 (4), 1145-1163.

[9] Kutney-Lee, A., Sloane, D., and Aiken, L. (2013). An increase in the number of nurses with baccalaureate degrees is linked to lower rates of post-surgery mortality. Health Affairs, 32 (3), 579-586.

[10] Yakushiva, O, Lindrooth, R, \& Weiss, D (2014a). Economic evaluation of the $80 \%$ Baccalaureate nurse workforce recommendation: A patient-level analysis. Medical Care 52 (10), 864-869.

[11] Yakushiva, O, Lindrooth, R, \& Weiss, D (2014b). Nurse value-added and patient outcomes in acute care. Health Services Research 49 (6), 1767-1786.

[12] Fardelione, C., Musil, C., Smith, E., and Click, E. (2014). Leadership behaviors of frontline staff nurses. The Journal of Continuing Education in Nursing, 45 (11), 506-513.

[13] Phillips, T., and Evans, J. (2017). RN to BSN transition: A concept analysis. Journal for Nurses in Professional Development, 33(2), 79-85.

[14] Matthias, A., and Kim-Goodwin, Y. (2016). RN-BSN students' perceptions of the differences in practice of the ADN- and BSN-Prepared RN. Nurse Educator, 41(4), 208-211.

[15] Washington Center for Nursing (2012-2016). Academic Progression in Nursing Grant $(\$ 600,000)$ from the Robert Wood Johnson Foundation. Retrieved from https://rwjf.org and https://www.academicprogression.org/learning_process/apingr antprojects/washington on (2016). 
[16] Washington Center for Nursing (2008). A Master Plan for Nursing Education in Washington State. Retrieved from https://www.wsac.wa.gov/sites/default/files/MasterPlan-Nurse s-WCN08.pdf on (2008).

[17] Babbo, G., Fought, S., Holk, M., Mulligan, A.M., \& Perrone, C. (2013). RN-to-BSN programs in the community college setting: Challenges and successes. Journal of Nursing Education, 52 (2), 85-90.

[18] Schaffner, M. (2013). Nursing program approval. Washington Nursing Commission News, 7 (4), 12. Retrieved from https://www.doh.wa.gov/Portals/1/Documents/Pubs/669256-F all2013.pdf (2013).

[19] Washington State Department of Health (2018). Nursing Education Programs 2016-2017 Annual School Report: Statistical Summary and Trends Analysis (DOH 669-269). Olympia, WA: Nursing Care Quality Assurance Commission.

[20] Hsieh, HF \& Shannon, SE (2005). Three approaches to qualitative content analysis. Qualitative Health Research 15(9), 1277-88.

[21] Elo, S \& Kyngas, H (2008). The qualitative content analysis process. Journal of Advanced Nursing 62(1), 107-15.

[22] Washington State Department of Health (2019). RN to BSN Approved Programs. Retrieved from https://www.doh.wa.gov/Portals/1/Documents/Mtgs/2019/AGNCQAC.pdf

[23] Girard, S., Hoeksel, R., Vandermause, R. and Eddy, L. (2017). Experiences of registered nurses who voluntarily withdraw from their BSN program. The Journal of Nursing Education, 56(5), 260-265.

[24] Duffy, M., Friesen, M., Speroni, K., Swengros, D., Shanks, L., Waiter, P., and Sheridan, M. (2014). BSN completion barriers, challenges, incentives, and strategies. The Journal of Nursing Administration, 44(4), 232-236.

[25] AACN. Special Survey on Vacant Faculty Positions. Retrieved from

https://www.aacnnursing.org/Portals/42/News/Surveys-Data/V acancy18.pdf. (2018).

[26] Schwarz, L., and Leibold, N. (2014). Perceived facilitators and barriers to baccalaureate degree completion among registered nurses with an associate's degree. The Journal of Continuing Education in Nursing, 45(4), 171-180.

[27] Olson, C., and Benham-Hutchins, M. (2019). Exploring online RN-to-BSN student perceptions of learner presence. Nursing Education Perspectives, pre-pub online.

[28] Stalter, A., Phillips, J., and Dolansky, M. (2017). QSEN Institute RN-BSN task force: White paper on recommendations for systems-based practice competency. Journal of Nursing Care Quality, 32, (4), 354-358.

[29] Stalter, A., and Jauch, A. (2019). Systems thinking education in RN-BSN programs. Nurse Educator, 44(2), 112-115.

[30] Docherty, A., Warkentin, P., Borgen, J., Garthe, K., Fischer, K. and Najjar, R. (2018). Enhancing student engagement: Innovative strategies for intentional learning. Journal of Professional Nursing, 34(6), 470-474.

[31] Washington State Department of Health (2014). RN to BSN Program Clinical Hours Requirement. Retrieved from https://app.leg.wa.gov/wac/default.aspx?cite=246-840-531 .

[32] Perfetto, L. (2019). Preparing the nurse of the future: Emergent themes in online RN-BSN education. Nursing Education Perspectives 40 (1), 18-24. 